\title{
Global patterns in the metacommunity structuring of lake macrophytes: regional variations and driving factors
}

\author{
Janne Alahuhta ${ }^{1,2}$ (1) $\cdot$ Marja Lindholm ${ }^{1}$. Claudia P. Bove ${ }^{3} \cdot$ Eglantine Chappuis $^{4} \cdot$ John Clayton $^{5} \cdot$ Mary de Winton $^{5}$. \\ Tõnu Feldmann $^{6}$ · Frauke Ecke ${ }^{7,8}$. Esperança Gacia ${ }^{4} \cdot$ Patrick Grillas ${ }^{9} \cdot$ Mark V. Hoyer ${ }^{10} \cdot$ Lucinda B. Johnson $^{11}$. \\ Agnieszka Kolada ${ }^{12} \cdot$ Sarian Kosten ${ }^{13} \cdot$ Torben Lauridsen $^{14} \cdot$ Balázs A. Lukács $^{15} \cdot$ Marit Mjelde $^{16} \cdot$ Roger P. Mormul $^{17}$.

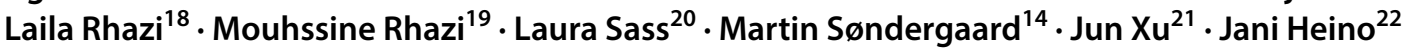

Received: 17 April 2018 / Accepted: 23 October 2018 / Published online: 29 October 2018

(c) The Author(s) 2018

\begin{abstract}
We studied community-environment relationships of lake macrophytes at two metacommunity scales using data from 16 regions across the world. More specifically, we examined (a) whether the lake macrophyte communities respond similar to key local environmental factors, major climate variables and lake spatial locations in each of the regions (i.e., within-region approach) and (b) how well can explained variability in the community-environment relationships across multiple lake macrophyte metacommunities be accounted for by elevation range, spatial extent, latitude, longitude, and age of the oldest lake within each metacommunity (i.e., across-region approach). In the within-region approach, we employed partial redundancy analyses together with variation partitioning to investigate the relative importance of local variables, climate variables, and spatial location on lake macrophytes among the study regions. In the across-region approach, we used adjusted $R^{2}$ values of the variation partitioning to model the community-environment relationships across multiple metacommunities using linear regression and commonality analysis. We found that niche filtering related to local lake-level environmental conditions was the dominant force structuring macrophytes within metacommunities. However, our results also revealed that elevation range associated with climate (increasing temperature amplitude affecting macrophytes) and spatial location (likely due to dispersal limitation) was important for macrophytes based on the findings of the across-metacommunities analysis. These findings suggest that different determinants influence macrophyte metacommunities within different regions, thus showing context dependency. Moreover, our study emphasized that the use of a single metacommunity scale gives incomplete information on the environmental features explaining variation in macrophyte communities.
\end{abstract}

Keywords Aquatic plants · Biogeography $\cdot$ Community structure $\cdot$ Elevation range $\cdot$ Environmental filtering Hydrophytes $\cdot$ Metacommunity ecology $\cdot$ Spatial processes $\cdot$ Spatial variation

\section{Introduction}

The continuing degradation of landscapes due to global change underscores the importance of understanding broad-scale patterns of biodiversity (Dudgeon et al. 2006;

Communicated by Bryan Brown.

Electronic supplementary material The online version of this article (https://doi.org/10.1007/s00442-018-4294-0) contains supplementary material, which is available to authorized users.

Janne Alahuhta

janne.alahuhta@oulu.fi

Extended author information available on the last page of the article
Vilmi et al. 2017). As a consequence, multi-discipline approaches are needed to understand biodiversity patterns and changes at various spatial scales. Biogeography and community ecology are two disciplines that share interests in investigating how historical events (e.g., glaciations), dispersal, biotic interactions, and environmental filtering structure biological communities at broad spatial and temporal extents (Brown and Lomolino 1998). Biogeography seeks to associate evolutionary, historical, and climatic influences on regional biota, and these biogeographic factors are typically strongly related to regional-scale diversity patterns (Svenning et al. 2008; Hortal et al. 2011). However, much uncertainty still exists in our understanding of the role of historical and climatic influences on local 
communities over broad extents, due in part to the lack of comparable data over large areas. Depending on the biological group and study region, the relative influence of history and climate vs. local environmental conditions on local community structure may differ. In some cases, history and climate have overcome the effects of local environmental conditions on local communities (Ricklefs and He 2016), whereas the opposite patterns have been found in other cases (Souffreau et al. 2015). Some studies have reported that both biogeographic characteristics and local environment have been important in explaining local community structure over broad spatial extents (Heino et al. 2017b; Rocha et al. 2017). These patterns can also be studied in the context of metacommunities, a discipline that connects biogeography and community ecology (Jenkins and Ricklefs 2011; Leibold and Chase 2018).

The main idea of metacommunity ecology is to understand the degree to which variation in local community structure is determined by environmental filtering and spatial dispersal processes (Winegardner et al. 2012; Heino et al. 2015b; Brown et al. 2016). The investigations of the relative contributions of these two processes are especially intriguing in lakes, which are island-like systems surrounded by terrestrial land uninhabitable for aquatic organisms (Hortal et al. 2014). Therefore, dispersal is challenging for species relying on watercourse connections for movement among lake habitats, although humans have acted as dispersal vectors for many organisms (see, e.g., Heino et al. 2017a). A recent meta-analysis also suggested that the importance of environmental filtering is the lowest in lakes when compared to other terrestrial and more connected aquatic ecosystem types (Soininen 2014). Other lake studies have found that biological assemblages with passive dispersal mode or large body size are more structured by spatial processes than local environmental conditions (Beisner et al. 2006; De Bie et al. 2012; Padial et al. 2014). However, a large amount of variation is present in the findings depending on the studied biological group, study region, and spatial extent, leading to context dependency in the patterns detected (Alahuhta and Heino 2013; Tonkin et al. 2016). One biological group showing context dependency has been aquatic macrophytes, many of which are distributed around the world due to efficient dispersal abilities and colonization strategies (Santamaría 2002; Chambers et al. 2008). Environmental filtering has thus often overruled spatial factors in explaining variation in macrophyte community structure (Capers et al. 2010; Mikulyuk et al. 2011; Alahuhta et al. 2013; Viana et al. 2014), although opposite patterns have been found in some metacommunities (Hájek et al. 2011; Padial et al. 2014). These conflicting patterns for aquatic macrophyte metacommunities call for a more holistic comparative analysis including data sets with identical explanatory variables from different regions globally.
Aquatic macrophytes often show large-scale biodiversity patterns that deviate from those found in many other biological groups. For example, although the latitudinal diversity gradient (i.e., the decrease in the number of species from the Equator to the poles) has been found for numerous biological groups in different ecosystems (Kinlock et al. 2018), macrophyte diversity often peaks at intermediate latitudes (Chappuis et al. 2012; Crow 1993). At regional extents, macrophyte diversity may show conflicting patterns in relation with latitude depending on the study region. For example, macrophytes have followed the latitudinal gradient in the Fennoscandia (Alahuhta et al. 2013), whereas a reversed pattern has been evidenced in the Midwestern USA (Johnston et al. 2010; Alahuhta 2015). Aquatic macrophytes may respond to climatic and elevational gradients at broad spatial scales, but these broad-scale characteristics are typically overcome by local environmental factors when accounting for variation in community structure (Kosten et al. 2011; Alahuhta 2015). For example, the macrophyte diversity-lake area relationship has varied from strongly positive to non-significant among studies conducted thus far (Jones et al. 2003; Hinden et al. 2005), likely because lake area may poorly describe the diversity-area relationship in deep lakes, where a large proportion of the lake is uninhabitable for macrophytes (Søndergaard et al. 2013). Depth gradient has often been negatively associated with macrophyte diversity, because the availability of light in water dictates photosynthesis rate for aquatic macrophytes (Kosten et al. 2009b; Søndergaard et al. 2013). Macrophytes also typically respond strongly to lake water chemistry (e.g., Chappuis et al. 2014). For example, aquatic macrophyte diversity has shown linear or unimodal in relation with total phosphorus, possibly because it is the primary nutrient for freshwater primary producers (Elser et al. 2007; Kosten et al. 2009a). However, it is difficult to draw comprehensive conclusions regarding how these environmental gradients structure aquatic macrophyte communities, due to inconsistencies among the studies (e.g., differences in spatial scales, explanatory variables, and methods used). Thus, investigations executed with identical study designs across multiple study sites and regions are needed to enhance our understanding of the relationships between aquatic macrophytes and environmental gradients (e.g., Borer et al. 2014; Heino et al. 2015a; Alahuhta et al. 2017a).

The overall purpose of this study was to investigate the community-environment relationships of lake macrophytes at the metacommunity scale using data sets collected from all over the world. More specifically, we studied (1) whether the lake macrophyte communities respond similar to key local environmental factors, major climate variables, and lake spatial locations in 16 study regions covering six continents (i.e., within-region approach, Figs. 1,2) how well can explained variability in the community-environment 


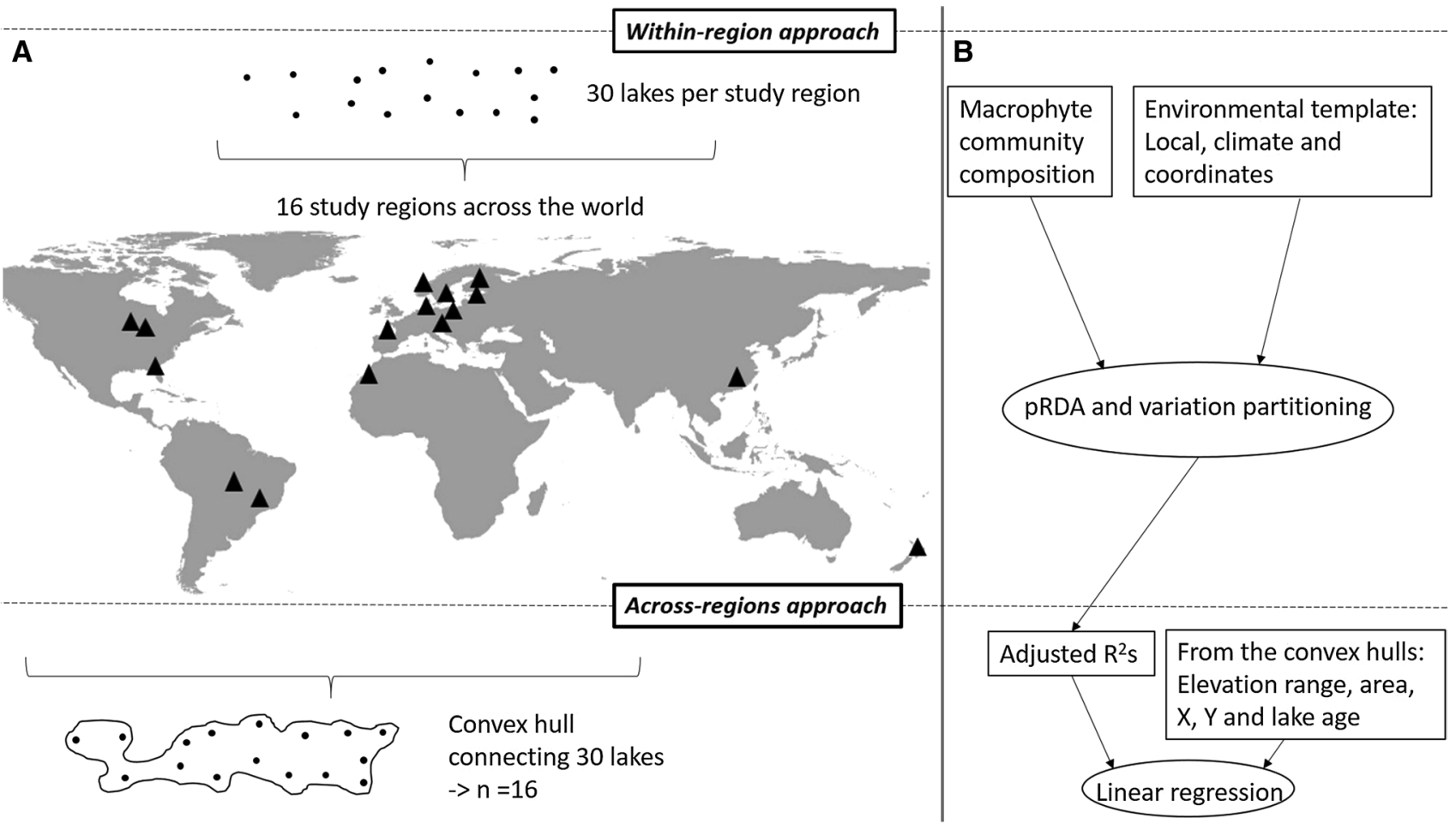

Fig. 1 Our study system comprised ca. 30 lakes surveyed in 16 metacommunities (black triangles) across the world. In the regional study approach, a convex hull that connected all 30 lakes in a region was drawn for each metacommunity separately, enabling us to obtain explanatory variables from the convex hull (a). We investigated lake macrophyte communities in relation with local variables, climate variables and lake coordinates separately in each metacommunity using partial redundancy analysis (pRDA) and variation partitioning (VP). Adjusted $R^{2}$ values gained from the VP for pure local and climate variables in addition to lake coordinates and full model including all three environmental variable groups were used as response variables in the across-region approach $(N=16)$. The adjusted $R^{2}$ values were regressed against a set of environmental variables (i.e., elevation range, area, geographic coordinates and estimated maximum lake age), which were obtained from a convex hull for each metacommunity (b). Metacommunity refers to 'within-region approach' and regional to 'across-region approach'
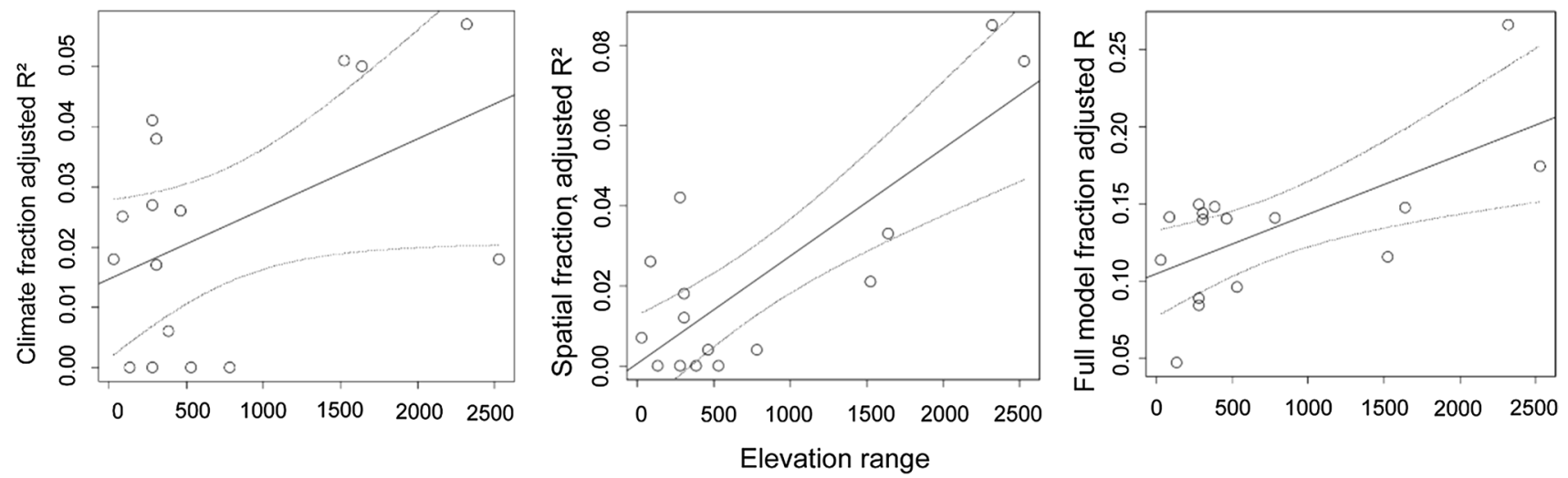

Fig. 2 Relationships between the adjusted $R^{2}$ values obtained through variation partitioning of pure climate fraction, spatial location fraction and full model of freshwater macrophytes and elevation range $(N=16)$

relationships across multiple lake macrophyte metacommunities be accounted for by elevation range, spatial extent, latitude, longitude, and age of the oldest lake within each metacommunity (i.e., across-region approach, Fig. 1). Based on the previous findings on lake macrophyte metacommunities from different regions (e.g., Capers et al. 2010; Mikulyuk et al. 2011; Alahuhta et al. 2013), we expected that environmental filtering should dominate over spatial 
factors in explaining macrophyte community structure, and this would be more apparent in stable and old lakes (i.e., of glacial origin) than in unstable young lakes, such as floodplain lakes. Because elevation range contributed strongly to global macrophyte turnover in a recent study (Alahuhta et al. 2017a), we hypothesized that elevation range would explain a large amount of variation in the across-region approach including multiple macrophyte metacommunities. Following the findings from a recent meta-analysis that a latitudinal diversity gradient does not exist for freshwater assemblages (Kinlock et al. 2018), we did not expect to find a significant relationship between the strength of community-environment relationships of macrophytes and latitude in the acrossregion approach. Finally, many terrestrial plants and trees have been shown to respond to historical effects, including the last glacial maximum (Svenning et al. 2008; Ordonez and Svenning 2016), and some studies have suggested that historical effects may be important also for macrophytes as well (Alahuhta et al. 2018). Based on this combined evidence, we suggest that the historical effect may have some influence on the strength of the community-environment relationships in the across-region approach.

\section{Materials and methods}

\section{Macrophyte data}

We surveyed lake macrophytes in 16 different regions covering six continents across the Earth (Table 1). Overall, 27-30 lakes were investigated in each region. In each region, we randomly chose ca. 30 lakes with similar geographical distribution from the pool of candidate lakes. The selected lakes ranged from floodplain lakes in Brazil and China to glacial-origin relatively stable lakes situated at boreal and temperate zones (e.g., Finland, Estonia, Sweden, Norway, Denmark, New Zealand, Poland, and US states of Minnesota and Wisconsin). Although the lakes differed in their environmental conditions among the regions, all lakes were mostly natural lentic systems (i.e., reservoirs were excluded). However, most of the lakes suffered from various anthropogenic pressures such as nutrient enrichment, alien invasive species, water-level fluctuations, and decreased connectivity. The inclusion of different types of lakes was considered an important factor increasing the range of environmental conditions, resulting in environmental filtering effects. Detailed descriptions of study lakes can be found in the Supporting Information (Appendix S1).

The macrophyte data consisted of presence-absence observations of hydrophyte species, i.e., species which grow exclusively in freshwaters. These hydrophytes consisted of submerged (elodeids and isoetids), free-floating (ceratophyllids and lemnids), floating-leaved, and emergent species (Cook 1999). Emergent hydrophytes included only those species strongly bound to aquatic environments and found to grow in water at the time of survey, like Alisma plantago-aquatica, Butomus umbellatus, Glyceria fluitans, Juncus bulbosus, Mentha aquatica, Sagittaria sagittifolia, and Schoenoplectus lacustris (Tanner et al. 1986; Crow 1993; Willby et al. 2000; Thomaz et al. 2003; Kosten et al. 2009a). In addition to non-aquatic emergent and shore species, charophytes and aquatic bryophytes were removed from the data sets, because only hydrophytes were exclusively surveyed in all the regions. We also excluded hybrids, subspecies, and genus level identifications when species from the same genus were recorded from the data. We refer to this set of aquatic species as macrophytes hereafter. All macrophytes were empirically surveyed using similar methods within each region. This enabled us to compare the strength of the community-environment relationships across the 16 regions and to minimize the potential negative influences caused by different survey methods within each region. The macrophyte surveys were executed mostly between 2001 and 2013. The exceptions were Norway and US states of Florida and Minnesota, which were surveyed in 1998, between 1991 and 2013, and between 1992 and 2003, respectively.

\section{Explanatory data: within-region approach}

To explore which factors explain the variability in macrophyte community structure within a region (a single metacommunity), we compiled three groups of lake-level variables: local variables, climate variables, and spatial location (Table 1). Local variables consisted of water total phosphorus concentration (mg/l), Secchi depth (m), and lake area $\left(\mathrm{km}^{2}\right)$. Secchi depth indicates various ecological responses, ranging from eutrophication to amount of humic substances in water and visibility (Chambers and Kalf 1984; Kosten et al. 2009b). Lake area is typically used to mirror species-area relationship for aquatic organisms (Jones et al. 2003; Alahuhta et al. 2013), but lake area does not necessarily comprehensively indicate this relationship in lakes, where a large extent of the lake is too deep for macrophyte colonization and growth (Mikulyuk et al. 2011; Søndergaard et al. 2013). However, data on maximum colonization depth were not available for all study lakes. Moreover, lake area is often highly correlated with shoreline length which mirrors species-area relationship relatively well for many aquatic organisms (Søndergaard et al. 2005; Lewin et al. 2014). These three local variables are among the most important explaining variation in lake macrophyte community structure, and often correlate with other water chemistry and hydromorphological variables that were not available for all the study lakes (Jones et al. 2003; Lacoul and Freedman 2006; Kosten et al. 2009a). Local variables were surveyed 


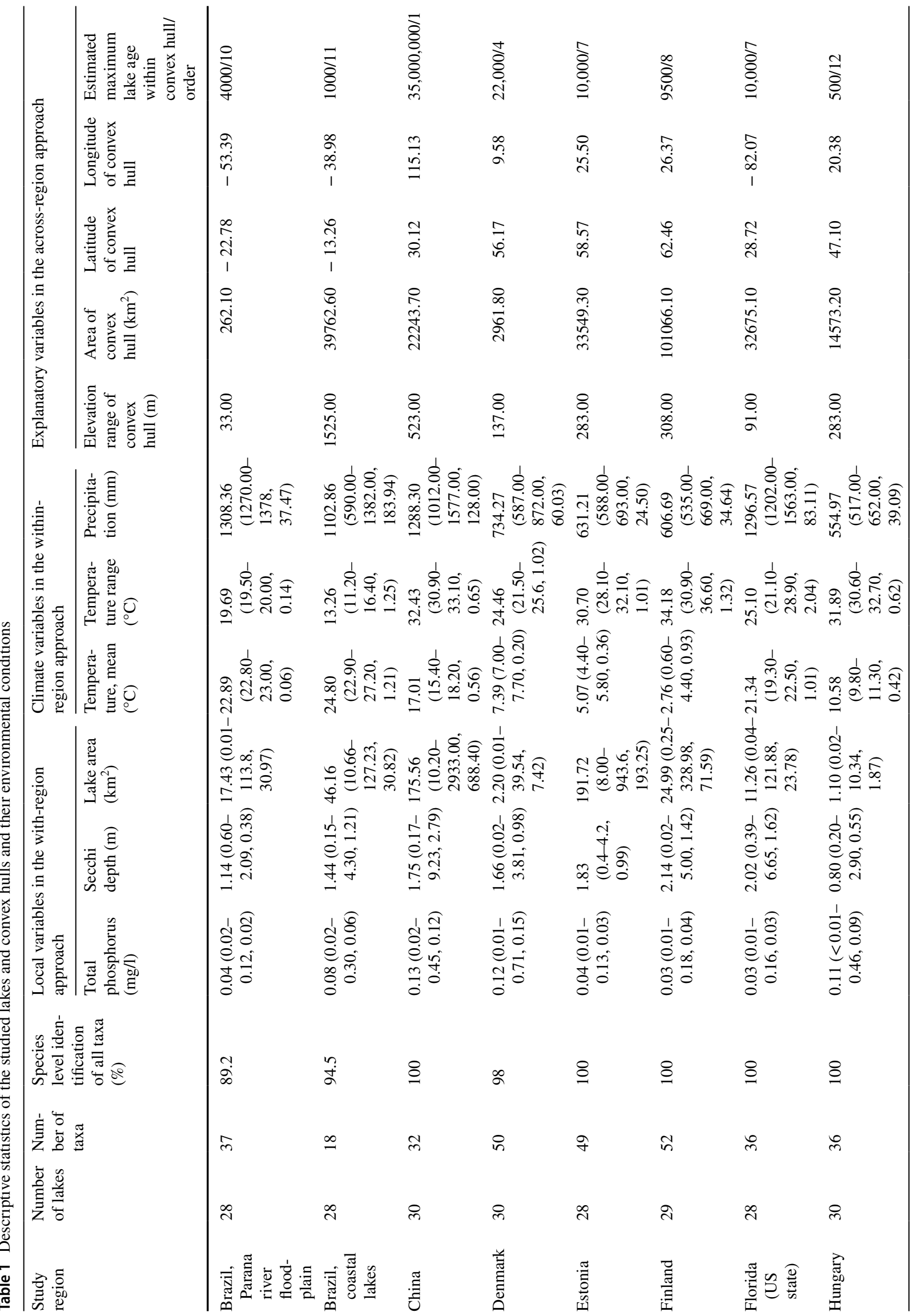




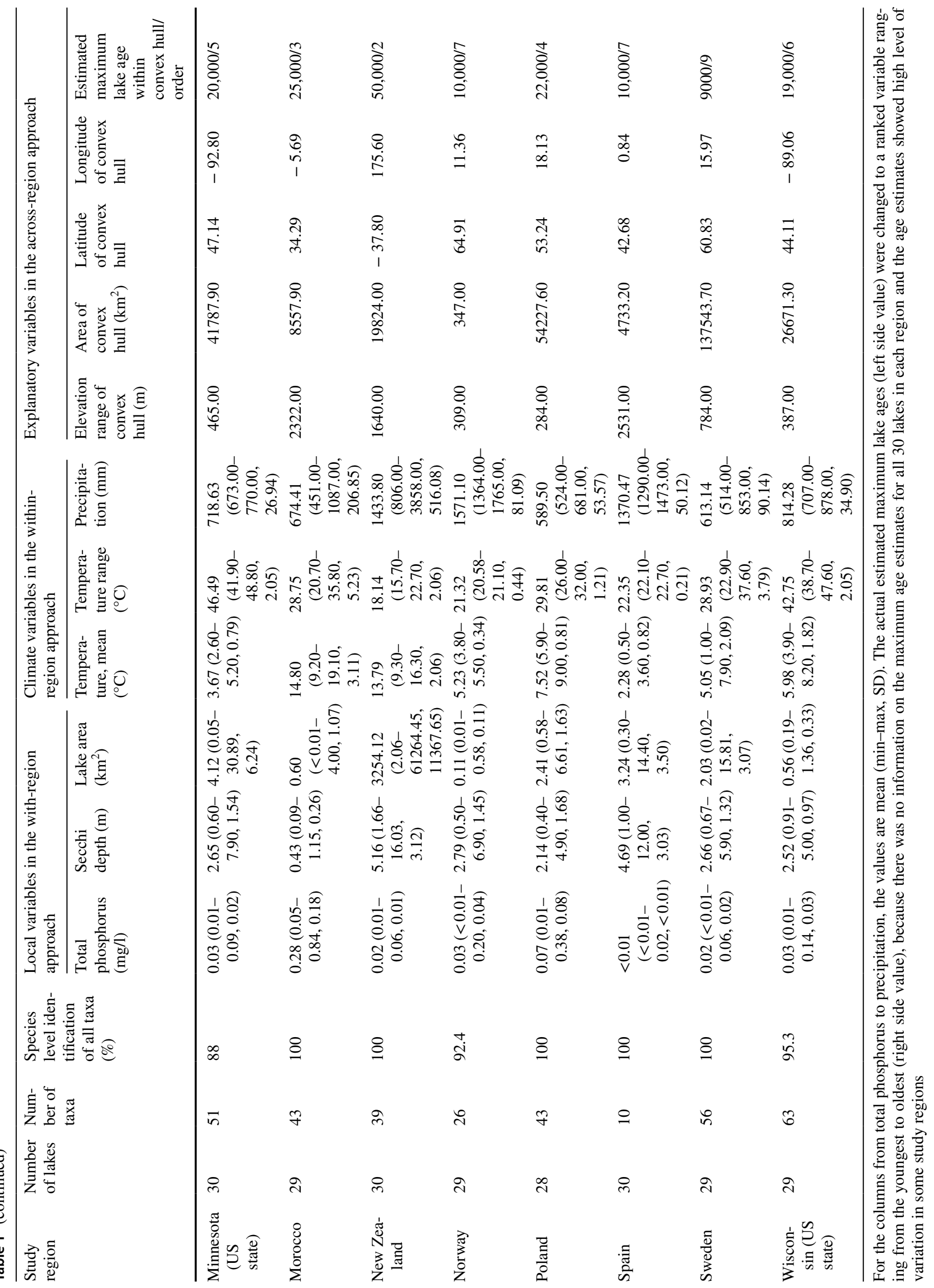


and determined similarly within each study region (Appen$\operatorname{dix} \mathrm{S} 1$ ).

Climate variables comprised atmospheric annual mean temperature $\left({ }^{\circ} \mathrm{C}\right)$, annual temperature range $\left({ }^{\circ} \mathrm{C}\right)$, and annual precipitation defined for each study lake based on 30 year average values obtained from the WorldClim (Hijmans et al. 2005). Annual mean air temperature was used as a proxy for thermal energy availability for macrophytes, whereas annual temperature range represented variation in thermal energy availability and its annual distribution in study lakes in different parts of the world (Kosten et al. 2009a; Alahuhta et al. 2017a). Annual precipitation was not only a surrogate for water-level fluctuation (incl. flooding and drying events) and potential dispersal via watercourses, but also for nutrient and material loading from the catchment (Soons et al. 2008; Carpenter et al. 2011). Climate variables were determined for each lake's center coordinate from $1 \mathrm{~km}$ resolution data, because it was not possible to extract values for a whole lake due to small surface area (i.e., $<1 \mathrm{~km}^{2}$ ) in many of the studied water bodies. Although we used atmospheric temperatures, they follow closely surface water temperatures across the world (O'Reilly et al. 2015).

Different methods, ranging from simple coordinates and trend surface analysis to principal coordinates of neighbor matrices analysis (PCNM), have been used to quantify spatial processes such as dispersal limitation (see a review for the freshwater realm, Heino et al. 2017a). However, none of these methods has proven superior for distinguishing spatial processes for local communities, especially when combined with variance partitioning (Gilbert and Bennett 2010; Smith and Lundholm 2010). In our work, geographic coordinates of lake centers were used to represent spatial locations among the 30 selected lakes within each study region; therefore, we utilized geographic coordinates, because we were interested only in broad-scale spatial patterns among the lakes. More importantly, we wanted to balance the study design by including the same number of environmental variables in each of the three lake-level explanatory variable groups to avoid type I error (Burnham and Anderson 2002). For example, the use of principal coordinates of neighbor matrices (PCNMs) analysis would have resulted to variable number of spatial variables in each study region, flawing our study design (e.g., Gilbert and Bennett 2010). However, to compare the results of these two methods (geographic coordinates vs. PCNMs) to obtain spatial variables, we also calculated PCNMs based on Euclidean distances among lakes separately in each metacommunity (Borcard and Legendre 2002).

\section{Explanatory data: across-region approach}

To investigate which characteristics structure the variability in macrophyte community structure across all regions (multiple metacommunities), we summarized regional environmental information within convex hulls encompassing the minimum area containing all surveyed lakes within each of the 16 regions (Heino et al. 2015a; Alahuhta et al. 2017a). For each study region, we defined elevation range within the convex hull $(\mathrm{m})$, area of the convex hull $\left(\mathrm{km}^{2}\right)$, latitude of the convex hull (from centroid), longitude of the convex hull (from centroid), and estimated the maximum age of the oldest lake within a particular study region (Table 1). Elevation range represented variability in habitats suitable for macrophytes and indicated temperature variation within a region (Wang et al. 2011; Alahuhta et al. 2017a). Elevation range was not sensitive to extreme values, as elevation range and quantile elevation range were significantly correlated ( $\left.R_{\text {Spearman }}: 0.75, p=0.0009\right)$. The convex hull area was used as a proxy for environmental heterogeneity (Gaston 2000). Both latitudinal and longitudinal gradients are known to affect freshwater species distributions (Chappuis et al. 2012; Griffiths et al. 2014). Longitude can indirectly affect macrophytes by indicating variation in large-scale climate (e.g., marine vs. continental climate), natural geological, soil or habitat properties, and land use changes (Kosten et al. 2009a; Sass et al. 2010; Alahuhta et al. 2017b). The age of the oldest lake was used as a surrogate for temporal availability of colonization sources for macrophyte species within each region. These estimates were based on literature and/ or sediment dating. However, there was no information on the maximum age estimates for all 30 lakes in each region and there was high variation in the age estimates in some study regions (e.g., based on sediment dating). For this reason, we considered that (a) it would not be possible to use lake-specific age estimates in the within-region approach, and (b) high variation in the actual values of age estimates would lead to serious lack of precision in the across-region approach. To overcome this problem, we changed the actual age estimations to a ranked variable ranging from the youngest (one) to oldest (12). Quadratic terms of these explanatory variables on the macrophytes were tested in the analysis, but these were not significant and were thus excluded from the analysis.

\section{Statistical analysis}

In the within-region (a single metacommunity) approach, we utilized partial redundancy analyses (pRDA) to distinguish the relationships between variation in macrophyte community composition and the three explanatory variable groups (i.e., local variables, climate variables, and spatial location), following the well-established variation partitioning protocol (Borcard et al. 1992). The species matrices were Hellinger-transformed prior to the RDAs to increase linearity of the studied gradients (Legendre and Gallagher 2001). Total variation in macrophyte community composition was 
partitioned into three independent and four shared fractions: (1) pure local variables; (2) pure climate variables; (3) pure spatial location; (4-7) their shared fractions; and (8) unexplained. The detailed procedures needed to calculate these fractions have been explained previously in the literature (Anderson and Cribble 1998; Borcard et al. 2011). As our main study purpose was to assess the relative importance of local variables, climate variables and spatial location among the study regions, we conducted variation partitioning separately for the 16 study regions using the same environmental variables. All environmental variables were forced in the pRDAs to maintain comparability among the study regions and to gain equal amount of information for the regional study approach (see below). The variation explained by each of the three variable group was evaluated using adjusted $\mathrm{R}^{2}$, which gives unbiased estimates of the explained variation (Peres-Neto et al. 2006). In addition, variation partitioning based on pRDA following the protocol described above was separately conducted between macrophyte community composition and local variables, climate variables, and PCNMs to find out whether the influence of spatial location differed when using either geographic coordinates or PCNMs. The suitable number of positively autocorrelated PCNMs was selected using the protocol of Blanchet et al. (2008), where all local and climate variables were forced in the models. The variation partitioning results (based on PCNMs) were not utilized in the across-region approach for the reasons explained above (in explanatory data: withinregion approach). The pRDAs and variation partitioning procedures were performed in the $\mathrm{R}$ environment with the vegan (Oksanen et al. 2013) and packfor (Blanchet et al. 2008) packages.

In the across-region (multiple metacommunities) approach, we used adjusted $\mathrm{R}^{2}$ values obtained from the pure fractions of variation partitioning (separately for the pure local, climate, and spatial variables, and for a full model including all variables) for each of the 16 study regions as response variables to study how the strength of the macrophyte community-environment relationships vary across the study regions. We used simple linear regression between the adjusted $R^{2}$ values and all environmental gradients (i.e., elevation range, area, latitude, longitude, and estimated maximum lake age within convex hulls) in the further analysis. Adjusted $R^{2}$ values of pure local variables were arcsine square root transformed prior to the analysis to achieve normality. To get additional information on the order of importance of different environmental gradients on the macrophytes across the study regions, we utilized commonality analysis to decompose linear regression effects to unique and common components (Nathans et al. 2012). The unique effects suggest how much variance is solely explained by a single explanatory variable, whereas common effects indicate how much variance is shared by two or more explanatory variables together (Ray-Mukherjee et al. 2014). A higher value of common effects compared to unique effect also suggests a greater collinearity among explanatory variables (Nathans et al. 2012; Ray-Mukherjee et al. 2014). In addition, negative values can occur in the common effects if some of the relationships among environmental variables have opposite trends (Ray-Mukherjee et al. 2014). Compared to other similar statistical methods, commonality analysis is independent of variable order that can disturb, for example, stepwise multiple regression results (Nathans et al. 2012; Petrocelli et al. 2003). Besides unique and common effects, we produced beta and structure coefficients. Beta coefficients indicate an environmental variable's total contribution to the regression equation, whereas structure coefficients are bivariate correlations between a predictor variable and the dependent variable's score resulting from the regression model (Nathans et al. 2012; Ray-Mukherjee et al. 2014). Unlike beta coefficients, structure coefficients are independent of collinearity among predictor variables (Ray-Mukherjee et al. 2014). Commonality analysis was executed using the 'yhat' package (Nimon et al. 2013) in the R environment.

\section{Results}

\section{Within-region approach}

The overall explained variation varied from $4.7 \%$ in Denmark to $26.6 \%$ in Morocco (Table 2). Of the pure fractions, local variables were most important for macrophyte metacommunities in 9 out of 16 regions. The explained variations of these pure local environmental fractions differed from $0.9 \%$ in Poland to $10.5 \%$ in China. The highest effect of pure fractions of climate variables was on metacommunities in Brazil coastal lakes (5.1\%) and New Zealand (5.1\%), while the highest effect of spatial location was on metacommunities in Morocco (8.5\%) and Spain (7.6\%). In addition, pure fractions of local and climate variables were equally high in the US states of Minnesota (2.4\% and 2.6\%, respectively) and Wisconsin $(0.90 \%$ and $0.56 \%$, respectively), whereas pure effects of climate (4.1\%) and spatial location (4.1\%) contributed similarly in Estonia. In addition, many joint fractions showed high-explained variation for macrophytes.

The joint effect of climate and spatial location was very important for macrophyte metacommunities in Brazil's Parana river floodplain (4.1\%), Hungary (5.8\%), Minnesota (6.9\%), Poland (5.4\%), and Wisconsin (12.9\%). Joint influence of all the three variable groups in Brazil's Parana river floodplain (5.3\%) and local and climate variables in Poland (3.0\%) explained considerable amount of variation for macrophytes. Other joint effects also showed a great amount of variation in China, Estonia, Morocco, New Zealand, and Sweden, but they were not as important as pure fractions. 
Table 2 Results of the variation partitioning (results shown as adjusted $R^{2}$ values $\times 100$ ) based on partial redundancy analysis (pRDA) in explaining the relationship between lake macrophyte communities and three environmental variable groups (i.e., local variables, climate variables and geographical variables) in each study region

\begin{tabular}{|c|c|c|c|c|c|c|c|c|}
\hline & $\begin{array}{l}\text { Local vari- } \\
\text { ables (LV) }\end{array}$ & $\begin{array}{l}\text { Climate vari- } \\
\text { ables }(\mathrm{CV})\end{array}$ & $\begin{array}{l}\text { Spatial } \\
\text { location } \\
(\mathrm{XY})\end{array}$ & $\mathrm{LV}+\mathrm{CV}$ & $\mathrm{CV}+\mathrm{XY}$ & $L V+X Y$ & $\mathrm{LV}+\mathrm{CV}+\mathrm{XY}$ & $\begin{array}{l}\text { Unex- } \\
\text { plained } \\
\text { variation }\end{array}$ \\
\hline Brazil, Parana river floodplain & 2.07 & 1.83 & 0.68 & -1.81 & 4.12 & -0.81 & 5.27 & 88.65 \\
\hline Brazil, coastal lakes & 1.71 & 5.05 & 2.09 & 3.35 & -1.69 & -0.66 & 1.70 & 88.45 \\
\hline China & 10.46 & 0.00 & 0.00 & -2.56 & 4.43 & 0.25 & 0.33 & 90.41 \\
\hline Denmark & 3.87 & 0.00 & 0.00 & 0.22 & 1.77 & 1.42 & -0.51 & 95.28 \\
\hline Estonia & 0.89 & 4.12 & 4.18 & 3.23 & 1.08 & 3.59 & -2.11 & 85.02 \\
\hline Finland & 5.23 & 1.65 & 1.78 & 3.25 & 1.27 & 0.04 & 0.79 & 86.00 \\
\hline Florida & 9.94 & 2.49 & 2.56 & 3.10 & -3.21 & 2.22 & -2.95 & 85.85 \\
\hline Hungary & 3.21 & 2.67 & 0.00 & -1.02 & 5.75 & 0.60 & -0.04 & 91.10 \\
\hline Minnesota & 2.43 & 2.63 & 0.36 & 0.19 & 6.94 & -0.21 & 1.69 & 85.97 \\
\hline Morocco & 2.54 & 5.66 & 8.53 & 0.93 & 5.79 & 0.04 & 3.11 & 73.40 \\
\hline New Zealand & 1.66 & 5.05 & 3.31 & -0.76 & 3.38 & -0.89 & 3.01 & 85.23 \\
\hline Norway & 7.76 & 3.79 & 1.16 & -1.44 & 2.14 & -2.69 & 3.66 & 85.62 \\
\hline Poland & 1.04 & 0.00 & -1.95 & 2.96 & 5.42 & 1.56 & 0.49 & 91.60 \\
\hline Spain & 6.06 & 1.81 & 7.55 & 1.17 & 1.80 & -1.82 & 0.85 & 82.58 \\
\hline Sweden & 7.17 & 0.00 & 0.37 & 3.40 & 5.36 & 0.28 & -1.20 & 85.91 \\
\hline Wisconsin & 0.90 & 0.56 & 0.00 & -0.24 & 12.94 & 0.52 & 0.23 & 85.21 \\
\hline
\end{tabular}

Separate pRDA analysis using identical explanatory variables was done for each study region. Significant $(p<0.05)$ pure fractions are bolded

Different individual variables were significant for macrophyte metacommunities in different study regions (Appendix S2).

Variation partitioning results using PCNMs as indicators of spatial influences differed to some extent from corresponding analyses, where spatial location was based on geographic location (Appendix S3). The contribution of pure spatial location based on PCNMs was higher than that based on geographic coordinates in China, Finland, Florida, Hungary, Morocco, and Norway. The opposite pattern was found in Estonia, Salga project lakes, and Spain. However, all selected PCNMs were first eigenvectors (Appendix S4), which indicate broad-scale variation in spatial patterns similar to that of geographic coordinates. We do not debate these results further due to potential issues elaborated in "Materials and methods".

\section{Across-region approach}

The linear regression models (regional variables vs. the explained variance in macrophyte community composition in the within-region variation partitioning) modestly explained the overall variation in macrophyte community composition in the across-region approach (Table 3 ). The adjusted $R^{2}$ from the linear models ranged from 0 (multiple $R^{2} 0.10$ ) for the pure local fraction of the variation partitioning to 0.56 (multiple $R^{2}=0.70$ ) for the pure spatial location of the variation partitioning. These low overall explained variations were to be expected due to the small number of regions $(n=16)$; however, we were most interested in whether, and to what extent, the regional explanatory variables would contribute to macrophytes in the across-region approach. None of the predictor variables significantly explained the pure local fraction.

Considering the climate fraction, the unique effect of elevation range was $15.0 \%$, although this value was not significant $(p=0.148)$. The structure coefficients of elevation range indicated a positive response to the pure climate fraction. Other predictors showed much smaller unique effects on the pure climate fraction. Latitude was the second most important predictor of pure climate fraction, but it also showed considerable level of collinearity with other predictors (i.e., high common effect). The pure spatial location fraction was significantly influenced by elevation range, which contributed $63.0 \%$ of the variation. The association between the pure spatial location fraction and elevation range was positive. Other predictors showed a minimal unique effect and/or a large common effect. For the full model, elevation range was the only significant predictor $(46.2 \%)$, having a positive relationship. Lake age also had a small negative unique effect on the full model.

\section{Discussion}

Single study regions inherently have region-specific environmental gradients (i.e., context dependency) which limits our abilities to draw comprehensive conclusions regarding 
Table 3 Results of commonality analysis for each environmental variable based on regression models for pure local adjusted $R^{2}$ values, pure climate adjusted $R^{2}$ values, pure broad-scale spatial pattern adjusted $R^{2}$ values, and full model adjusted $R^{2}$ values

\begin{tabular}{|c|c|c|c|c|c|c|c|c|c|}
\hline Environmental variable & Estimate & SE & $t$ & $p$ & $\beta$ & $\mathrm{SC}$ & Unique & Common & Total \\
\hline \multicolumn{10}{|l|}{ Pure local adj. $R^{2}$} \\
\hline Elevation range & $<0.001$ & $<0.001$ & -0.015 & 0.988 & -0.005 & -0.165 & $<0.001$ & 0.003 & 0.003 \\
\hline Area & $<0.001$ & $<0.001$ & 0.103 & 0.920 & 0.034 & 0.410 & 0.001 & 0.016 & 0.017 \\
\hline$X$ & $<0.001$ & $<0.001$ & 0.559 & 0.588 & 0.198 & 0.402 & 0.028 & -0.012 & 0.016 \\
\hline$Y$ & 0.001 & 0.001 & 0.838 & 0.422 & 0.284 & 0.830 & 0.063 & 0.002 & $\underline{0.065}$ \\
\hline Lake age & 0.001 & 0.009 & 0.065 & 0.949 & 0.023 & -0.169 & $<0.001$ & 0.003 & 0.003 \\
\hline \multicolumn{10}{|l|}{ Pure climate adj. $R^{2}$} \\
\hline Elevation range & $<0.001$ & $<0.001$ & 1.567 & 0.148 & 0.416 & 0.768 & 0.150 & 0.079 & $\underline{0.229}$ \\
\hline Area & $<0.001$ & $<0.001$ & -0.890 & 0.394 & -0.243 & -0.506 & 0.049 & 0.051 & 0.100 \\
\hline$X$ & $<0.001$ & $<0.001$ & 0.190 & 0.853 & 0.055 & 0.130 & 0.002 & 0.004 & 0.007 \\
\hline$Y$ & $<0.001$ & $<0.001$ & -0.740 & 0.476 & -0.207 & -0.664 & 0.034 & 0.138 & 0.171 \\
\hline Lake age & 0.002 & 0.002 & -0.841 & 0.420 & 0.245 & 0.146 & 0.043 & -0.035 & 0.008 \\
\hline \multicolumn{10}{|c|}{ Pure spatial location adj. $R^{2}$} \\
\hline Elevation range & $<0.001$ & $<0.001$ & 4.613 & $0.001 * *$ & 0.851 & 0.961 & 0.630 & 0.020 & $\underline{0.650}$ \\
\hline Area & $<0.001$ & $<0.001$ & -0.952 & 0.363 & -0.180 & -0.292 & 0.027 & 0.033 & 0.060 \\
\hline$X$ & $<0.001$ & $<0.001$ & -0.351 & 0.733 & -0.071 & 0.095 & 0.004 & 0.003 & 0.006 \\
\hline$Y$ & $<0.001$ & $<0.001$ & 0.938 & 0.370 & 0.183 & -0.130 & 0.026 & -0.014 & 0.012 \\
\hline Lake age & $<0.001$ & 0.002 & 0.032 & 0.975 & 0.006 & -0.185 & 0.000 & 0.024 & 0.024 \\
\hline \multicolumn{10}{|l|}{ Full model adj. $R^{2}$} \\
\hline Elevation range & $<0.001$ & $<0.001$ & 3.124 & $0.011 * *$ & 0.729 & 0.890 & 0.462 & -0.044 & $\underline{0.418}$ \\
\hline Area & $<0.001$ & $<0.001$ & 0.429 & 0.677 & 0.103 & -0.022 & 0.009 & -0.009 & $<0.001$ \\
\hline$X$ & $<0.001$ & $<0.001$ & -1.295 & 0.225 & -0.332 & -0.141 & 0.079 & -0.069 & 0.011 \\
\hline$Y$ & $<0.001$ & $<0.001$ & 0.354 & 0.731 & 0.087 & -0.040 & 0.006 & -0.005 & 0.001 \\
\hline Lake age & -0.003 & 0.004 & -0.699 & 0.501 & -0.179 & -0.200 & 0.023 & -0.002 & 0.021 \\
\hline
\end{tabular}

A higher value of common effects compared to unique effect also suggests a greater collinearity among explanatory variables. Additionally, negative values can occur in the common effects if some of the relationships among environmental variables have opposite trends. Beta coefficients indicate an environmental variable's total contribution to the regression equation, whereas structure coefficients are bivariate correlations between a predictor variable and the dependent variable's score resulting from the regression model. Note that structure coefficients are independent of collinearity among predictor variables (Ray-Mukherjee et al. 2014)

$S E$ standard error, $\beta$ beta coefficients, $S C$ structure coefficients, Unique unique effect of variation for each environmental variable in the regression models, Common shared effect of variation for each environmental variable in the regression models, total combined effect (i.e., sum of unique and common effects) of variation for each environmental variable in the regression models

$p<0.05$ : **, higher Common than Unique values (indicating collinearity) in italic font, highest Unique values in each group in bold font, and highest total values in each group are underlined

how these gradients structure local communities across multiple regions and globally (Kraft et al. 2011; Heino et al. 2015a). To overcome this problem, we studied community-environment relationships of lake macrophytes at two metacommunity scales (i.e., within region and across regions) using data sets from 16 regions on six continents. Our study revealed that niche processes related to local lakelevel environmental conditions are the dominant force structuring macrophytes within metacommunities. However, our findings also suggest that spatial location, possibly referring to dispersal limitation, is important based on the findings of the across-metacommunities analysis, because species may not be able disperse freely across lakes (Heino et al. 2017a). In addition, elevation range being the only significant predictor influencing the strength of the community-environment relationships across metacommunities suggests that increasing climate variation along with wider elevation range strongly drives the variation in macrophyte communities.

\section{Environmental filtering prevails, but context dependency occurs within metacommunities}

The overall explained variation remained relatively modest in all regions. This has been found in numerous freshwater metacommunities comprising different biological groups (Beisner et al. 2006; O'Hare et al. 2012; Alahuhta and Heino 2013; Heino et al. 2015a). However, we were able to detect subtle patterns in macrophyte metacommunities that existed in most of the study regions. In general, we found that environmental filtering overrode the effects of spatial factors in 
explaining local communities, but our results conflict with those of other studies conducted in lake ecosystems (Padial et al. 2014; Soininen 2014). We discovered that local environmental variables were more important than spatial location in shaping macrophyte communities in most of the 16 study regions. Thus, our findings lend support to the previous studies on aquatic macrophytes conducted at regional extents (Capers et al. 2010; Alahuhta et al. 2013; Viana et al. 2014), showing that environmental filtering is a dominant force structuring macrophyte metacommunities. To our surprise, we found no differences in this pattern between locally more stable and fluctuating lakes. For example, floodplain lakes of Brazil and China were also mainly explained by environmental filtering, a finding that held across boreal lakes of glacial origin.

The observed dominant role of environmental filtering was found to be rather consistent among the study regions despite their variable spatial extents. This contrasts with earlier findings that suggested that the influence of spatial processes had been expected to increase with increasing extent (Leibold et al. 2004; Soininen 2014; Heino et al. 2015b). The spatial extent of our study regions varied from $260 \mathrm{~km}^{2}$ in Norway to $138,000 \mathrm{~km}^{2}$ in Sweden, but no systematic increase in the effects of spatial processes was noted along with increasing extent. This outcome may be because environmental gradients often become wider with increasing spatial extent, offering more dimensions for environmental filtering to predominate as long as dispersal remains adequate (Leibold et al. 2004; Heino et al. 2017b).

Spatial processes were most important only in the study regions with highly variable elevation (Morocco and Spain), indicating potential dispersal limitation among the studied lakes within these metacommunities. Mountainous environments may create dispersal obstacles or hinder movement in these two study regions. Similar patterns have been observed for different freshwater organism groups in other topographically diverse regions (Hoeinghaus et al. 2007; Wang et al. 2011). This finding suggests that aquatic macrophyte metacommunities are driven by environmental filtering among lakes when no major dispersal barrier related to topography exists in a region, whereas dispersal limitation is of greater importance in topographically variable regions.

In addition to environmental filtering, lake macrophytes in few regions were affected by climatic forcing, suggesting that other biogeographic effects also contribute to local communities. Although pure climate variables were the most important drivers of macrophyte metacommunities only in coastal lakes of Brazil and New Zealand, the joint effect of climate and spatial location dominated over other fractions in four regions. Climate shows clear geographical trends in relation with latitude, longitude, and elevation at broad extents (Willis and Whittaker 2002), leading to spatial structuring of climate variables as in our study. Temperature affects physiology of aquatic macrophytes by determining, for example, their seed germination as well as onset and rate of seasonal growth (Lacoul and Freedman 2006). Macrophytes are also sensitive to cold temperatures and seasonal variations of temperature (Rooney and Kalff 2000; Netten et al. 2011). In addition, climate may indirectly indicate human colonization (e.g., introduction of alien invasive species and land use) when the colonization has a strong latitudinal or longitudinal gradient (Sass et al. 2010; Alahuhta et al. 2017b). In our study, this kind of phenomenon is possible especially in New Zealand.

These findings within metacommunities may have been influenced to some extent by the limited number of explanatory variables. Additional water chemistry and hydromorphology variables could have increased the importance of local environmental variables at least in some macrophyte metacommunities. For example, alkalinity and maximum colonization depth strongly drive macrophyte community variation in many regions (Lacoul and Freedman 2006; Alahuhta and Heino 2013; Søndergaard et al. 2013); however, these local environmental variables were not available for all the study lakes. Moreover, the water chemistry variables we used are often correlated with many of the local variables absent from our study (Johnson et al. 1997; Wagner et al. 2011). In addition, the use of water instead of atmospheric temperatures might have strengthened the species-climate relationships, although the atmospheric temperatures closely mirror water temperatures in most lakes, especially in unstratified ones (O'Reilly et al. 2015). Despite these possible shortcomings, the environmental variables we utilized were carefully selected to indicate specific ecological responses by lake macrophytes (see Austin (2002) for the ecological rational for variable selection).

\section{Elevation range explains the strength of the community-environment relationships across metacommunities}

We expected that elevation range would strongly affect the strength of the community-environment relationships in the across-metacommunities approach. We found clear support for this hypothesis, as the elevation range significantly explained variation in the climate and spatial location fractions and in the full RDA models. Alahuhta et al. (2017a) discovered that the beta diversity of macrophytes was best controlled by elevation range, which was also related to environmental heterogeneity. They also suggested that temperature variability was one of the fundamental mechanisms behind the patterns detected. Our finding on the relationship between the climate fraction and elevation range similarly indicated that wider elevation range leads to increasing temperature amplitude that, in turn, affects macrophyte communities. This observation 
highlights the fact that although climate was not the primary driver of macrophytes within a metacommunity at regional extents, its influence is vital across the metacommunities in affecting the strength of the community-environment relationships. In this respect, our results follow the findings from other ecosystems that climate is an important biogeographical characteristic structuring various biological organism groups at the broadest extents. This is likely due to lack of the previous empirical analyses on the community-climate relationships on lake macrophytes at global extents, providing inadequate information on this biogeographical pattern for these organisms.

In addition to the linkage with climate fraction, elevation range was also significantly related to the spatial location fraction. This finding is likely related to dispersal limitation, because wide elevation ranges increase the likelihood of dispersal barriers in the environment. If a dispersal barrier is found in the environment, then an isolated spatial location of local communities hinders possibilities for a community to receive colonists and propagules (Heino et al. 2017a). This outcome follows the ideas of metacommunity ecology that dispersal limitation should exist at the broadest extents (Soininen 2014; Heino et al. 2015b). Moreover, the potential dispersal limitation in macrophyte metacommunities found in this study is highly interesting considering that many macrophyte species have been recorded in more than one continent, suggesting that dispersal limitation has only marginal effect on lake macrophytes (Santamaría 2002; Chambers et al. 2008). In addition, many macrophytes are invasive species, which could overcome dispersal limitation due to the international trade and human-mediated environmental changes (Meyerson and Mooney 2007; Van Kleunen et al. 2015).

Other predictors had only a minimal contribution to any of the across-metacommunities-related fractions. Convex hull area had some influence on the climate fraction; however, the pattern was negative. As expected, latitude was not very strongly related to macrophytes. Latitude was slightly negatively correlated with the climate fraction, although the value of common effects clearly exceeded that of unique effects, indicating collinearity with other predictors. Besides, latitude and longitude acted as suppressors for the spatial location fraction and the full model that had minimal shared variance with the dependent variable, but still made some contribution to the regression model (Ray-Mukherjee et al. 2014). In addition, we found little association between the local environmental fraction and the predictors, suggesting that these biogeographical factors have no effect on the strength of the community-environment relationships. This finding is logical, as local environmental variables (e.g., water chemistry) do not show any clear spatial trend at broad extents, but they can strongly vary even between adjacent water bodies (e.g., Elser et al. 2007).
To our surprise, lake age had no consistent effect on macrophytes across the metacommunities. However, our simple ranked lake age variable may not be sensitive enough to capture historical effects on macrophyte communities. For example, Alahuhta et al. (2018) found that melting of glacial sheet ca. 10000 years ago created variable local environmental conditions in the boreal landscape, further affecting present-day community composition of lake macrophytes in Finland. On the other hand, basin identity representing historical effects was an important factor explaining variation in the community structure of different freshwater organism groups in boreal lakes and rivers (Heino et al. 2017b). Moreover, we recognize that the present study is the first attempt to account for the historical effects on macrophyte communities at global extents, and therefore, more research on this topic is clearly needed.

\section{Concluding remarks}

Our comprehensive study using data on lake macrophytes from 16 regions at two metacommunity scales (within and across metacommunities) sheds light on their community-environment relationships, which often display variable results when different regions are compared. We found that environmental filtering typically dominated over spatial processing in explaining lake macrophytes within metacommunities. We also discovered that the use of the single metacommunity scale gives inadequate information on the environmental patterns explaining variation in macrophyte communities. For example, macrophyte communities were typically not dispersal limited within metacommunities, but spatial barriers seemed to have hindered the movements of macrophytes in some regions when the results of the across-metacommunities analysis were incorporated. Similarly, climate effects related to elevation range were the only predictor of the strength of the community-environment relationships across metacommunities, although climatic influence was limited within individual metacommunities. These complementary results from two metacommunity scales emphasize the need to integrate community ecology and biogeography when variations in local communities are studied. Our findings provide a greater understanding of community variation and the underlying factors, which should contribute to more efficient management strategies aiming to limit biodiversity loss in freshwater ecosystems.

Acknowledgements Open access funding provided by University of Oulu including Oulu University Hospital. JA appreciates financial support from the Ella and Georg Ehrnrooth Foundation. BAL was supported by National Research, Development and Innovation Office-NKFIH, OTKA PD120775 Grant and by the Bolyai János Research Scholarship of the Hungarian Academy of Sciences. S.K. was supported by NWO Veni grant 86312012 . Sampling of the coastal 
Brazilian lakes was financed by NWO grant W84-549; The National Geographic Society grant 7864-5; and CNPq grants 480122, 490409, 311427. We thank the SALGA team, especially Gissell Lacerot, Nestor Mazzeo, Vera Huszar, David da Motta Marques, and Erik Jeppesen for organizing and executing the SALGA field sampling campaign and Bruno Irgang $\dagger$ and Eduardo Alonso Paz for help with identification. We thank Minnesota and Wisconsin Departments of Natural Resources for collecting the macrophyte data. We are especially grateful to Carol Reschke, University of Minnesota Duluth, for her work in combining and performing quality control for the Minnesota macrophyte data used in the analysis. This is contribution no. 607 of the Natural Resources Research Inst. of the Univ. of Minnesota Duluth. Provision of New Zealand macrophyte data was possible via NIWA SSIF funding.

Author contribution statement JA and JH designed the study and wrote the first draft of the manuscript; all authors except JH and ML contributed data; JA compiled the data; JA and ML processed the data; JA analyzed the data. All authors contributed critically to the draft and gave final approval for publication.

Data accessibility Many of the data sets are from state or national administration, where they can be obtained by request.

Open Access This article is distributed under the terms of the Creative Commons Attribution 4.0 International License (http://creativeco mmons.org/licenses/by/4.0/), which permits unrestricted use, distribution, and reproduction in any medium, provided you give appropriate credit to the original author(s) and the source, provide a link to the Creative Commons license, and indicate if changes were made.

\section{References}

Alahuhta J (2015) Geographic patterns of lake macrophyte communities and species richness at regional scale. J Veg Sci 26:564-575. https://doi.org/10.1111/jvs.12261

Alahuhta J, Heino J (2013) Spatial extent, regional specificity and metacommunity structuring in lake macrophytes. J Biogeogr 40:1572-1582. https://doi.org/10.1111/jbi.12089

Alahuhta J, Kanninen A, Hellsten S et al (2013) Environmental and spatial correlates of community composition, richness and status of boreal lake macrophytes. Ecol Indic 32:172-181. https://doi. org/10.1016/j.ecolind.2013.03.031

Alahuhta J, Kosten S, Akasaka M et al (2017a) Global variation in the beta diversity of lake macrophytes is driven by environmental heterogeneity rather than latitude. J Biogeogr 44:1758-1769. https ://doi.org/10.1111/jbi.12978

Alahuhta J, Virtala A, Hjort J et al (2017b) Average niche breadths of species in lake macrophyte communities respond to ecological gradients variably in four regions on two continents. Oecologia 184:219-235. https://doi.org/10.1007/s00442-017-3847-y

Alahuhta J, Hellsten S, Kuoppala M, Riihimäki J (2018) Regional and local determinants of macrophyte community compositions in high-latitude lakes of Finland. Hydrobiologia 812:99-114. https ://doi.org/10.1007/s10750-016-2843-2

Anderson MJ, Cribble NA (1998) Partitioning the variation among spatial, temporal and environmental components in a multivariate data set. Aust J Ecol 23:158-167. https://doi. org/10.1111/j.1442-9993.1998.tb00713.x

Austin MP (2002) Spatial prediction of species distribution: an interface between ecological theory and statistical modelling. Ecol Model 157:101-118. https://doi.org/10.1016/S0304 $-3800(02) 00205-3$
Beisner BE, Pere-Net PR, Lindström ES et al (2006) The role of environmental and spatial processes in struturing lake communities from bacteria to fish***. Ecology 87:2985-2991

Blanchet FG, Legendre P, Borcard D (2008) Forward selection of explanatory variables. Ecology 89:2623-2632. https://doi. org/10.1890/07-0986.1

Borcard D, Legendre P (2002) All-scale spatial analysis of ecological data by means of principal coordinates of neighbour matrices. Ecol Modell 153:51-68. https://doi.org/10.1016/S0304 $-3800(01) 00501-4$

Borcard D, Legendre P, Drapeau P (1992) Partialling out the spatial component of ecological variation. Ecology 73:1045-1055

Borcard D, Gillet F, Legendre P (2011) Numerical ecology with R. Springer, New York, p 306

Borer ET, Harpole WS, Adler PB et al (2014) Finding generality in ecology: a model for globally distributed experiments. Methods Ecol Evol 5:65-73. https://doi.org/10.1111/2041-210X.12125

Brown JH, Lomolino MV (1998) Biogeography, 2nd edn. Sinauer Associates Inc, Sunderland, p 691

Brown BL, Sokol ER, Skelton J, Tornwall B (2016) Making sense of metacommunities: dispelling the mythology of a metacommunity typology. Oecologia. 5:6-7. https://doi.org/10.1007/s0044 2-016-3792-1

Burnham KP, Anderson DR (2002) Model Selection and MultimodeIInference. A practical Information-Theoretic Approach. Springer, New York, NY

Capers RS, Selsky R, Bugbee GJ (2010) The relative importance of local conditions and regional processes in structuring aquatic plant communities. Freshw Biol 55:952-966. https://doi.org/10 $.1111 / \mathrm{j} .1365-2427.2009 .02328 . x$

Carpenter SR, Stanley EH, Vander Zanden MJ (2011) State of the world's freshwater ecosystems: physical, chemical, and biological changes. Annu Rev Environ Resour 36:75-99. https://doi. org/10.1146/annurev-environ-021810-094524

Chambers PA, Kalf J (1984) Depth distribution and biomass of submerged aquatic macrophyte communities in relation to Secchi depth. Can J Fish Aquat Sci 42:701-709

Chambers PA, Lacoul P, Murphy KJ, Thomaz SM (2008) Global diversity of aquatic macrophytes in freshwater. Hydrobiologia 595:9-26. https://doi.org/10.1007/s10750-007-9154-6

Chappuis E, Ballesteros E, Gacia E (2012) Distribution and richness of aquatic plants across Europe and Mediterranean countries: patterns, environmental driving factors and comparison with total plant richness. J Veg Sci 23:985-997. https://doi.org/10.111 1/j.1654-1103.2012.01417.x

Chappuis E, Gacia E, Ballesteros E (2014) Environmental factors explaining the distribution and diversity of vascular aquatic macrophytes in a highly heterogeneous Mediterranean region. Aquat Bot 113:72-82. https://doi.org/10.1016/j.aquabot.2013.11.007

Cook CDK (1999) The number and kinds of embryo-bearing plants which have become aquatic: a survey. Perspect Plant Ecol Evol Syst 2:79-102. https://doi.org/10.1078/1433-8319-00066

Crow GE (1993) Species diversity in aquatic angiosperms: latitudinal patterns. Aquat Bot 44:229-258. https://doi.org/10.1016/03043770(93)90072-5

De Bie T, De Meester L, Brendonck L et al (2012) Body size and dispersal mode as key traits determining metacommunity structure of aquatic organisms. Ecol Lett 15:740-747. https://doi.org/10.1 111/j.1461-0248.2012.01794.x

Dudgeon D, Arthington AH, Gessner MO et al (2006) Freshwater biodiversity: importance, threats, status and conservation challenges. Biol Rev 81:163. https://doi.org/10.1017/S1464793105006950

Elser JJ, Bracken MES, Cleland EE et al (2007) Global analysis of nitrogen and phosphorus limitation of primary producers in freshwater, marine and terrestrial ecosystems. Ecol Lett 10:1135-1142. https://doi.org/10.1111/j.1461-0248.2007.01113.x 
Gaston KJ (2000) Global patterns in biodiversity. Nature 405:220-227. https://doi.org/10.1038/35012228

Gilbert B, Bennett JR (2010) Partitioning variation in ecological communities: do the numbers add up? J Appl Ecol 47:1071-1082. https://doi.org/10.1111/j.1365-2664.2010.01861.x

Griffiths D, Mcgonigle C, Quinn R (2014) Climate and species richness patterns of freshwater fish in North America and Europe. $\mathrm{J}$ Biogeogr 41:452-463. https://doi.org/10.1111/jbi.12216

Hájek M, Roleček J, Cottenie K et al (2011) Environmental and spatial controls of biotic assemblages in a discrete semi-terrestrial habitat: comparison of organisms with different dispersal abilities sampled in the same plots. J Biogeogr 38:1683-1693. https ://doi.org/10.1111/j.1365-2699.2011.02503.x

Heino J, Melo AS, Bini LM et al (2015a) A comparative analysis reveals weak relationships between ecological factors and beta diversity of stream insect metacommunities at two spatial levels. Ecol Evol 5:1235-1248. https://doi.org/10.1002/ece3.1439

Heino J, Melo AS, Siqueira T et al (2015b) Metacommunity organisation, spatial extent and dispersal in aquatic systems: patterns, processes and prospects. Freshw Biol 60:845-869. https://doi. org/10.1111/fwb. 12533

Heino J, Alahuhta J, Ala-Hulkko T et al (2017a) Integrating dispersal proxies in ecological and environmental research in the freshwater realm. Environ Rev 25:334-349. https://doi.org/10.1139/ er-2016-0110

Heino J, Soininen J, Alahuhta J et al (2017b) Metacommunity ecology meets biogeography: effects of geographical region, spatial dynamics and environmental filtering on community structure in aquatic organisms. Oecologia 183:121-137. https://doi. org/10.1007/s00442-016-3750-y

Hijmans RJ, Cameron SE, Parra JL et al (2005) Very high resolution interpolated climate surfaces for global land areas. Int J Climatol 25:1965-1978. https://doi.org/10.1002/joc. 1276

Hinden H, Oertli B, Menetrey N et al (2005) Alpine pond biodiversity: what are the related environmental variables? Aquat Conserv Mar Freshw Ecosyst 15:613-624. https://doi.org/10.1002/ aqc. 751

Hoeinghaus DJ, Winemiller KO, Birnbaum JS (2007) Local and regional determinants of stream fish assemblage structure: inferences based on taxonomic vs. functional groups. J Biogeogr 34:324-338. https://doi.org/10.1111/j.1365-2699.2006.01587.x

Hortal J, Diniz-Filho JAF, Bini LM et al (2011) Ice age climate, evolutionary constraints and diversity patterns of european dung beetles. Ecol Lett 14:741-748. https://doi.org/10.111 1/j.1461-0248.2011.01634.x

Hortal J, Nabout JC, Calatayud J et al (2014) Perspectives on the use of lakes and ponds as model systems for macroecological research. $\mathrm{J}$ Limnol 73:46-60. https://doi.org/10.4081/jlimnol.2014.887

Jenkins DG, Ricklefs RE (2011) Biogeography and ecology: two views of one world. Philos Trans R Soc B Biol Sci 366:2331-2335. https ://doi.org/10.1098/rstb.2011.0064

Johnson L, Richards C, Host G, Arthur J (1997) Landscape influences on water chemistry in Midwestern stream ecosystems. Freshw Biol 37:193-208. https://doi.org/10.1046/j.1365-2427.1997. d01-539.x

Johnston CA, Zedler JB, Tulbure MG (2010) Latitudinal gradient of floristic condition among Great Lakes coastal wetlands. J Great Lakes Res 36:772-779. https://doi.org/10.1016/j.jglr.2010.09.001

Jones JI, Li W, Maberly SC (2003) Area, altitude and aquatic plant diversity. Ecography (Cop) 26:411-420. https://doi.org/10.103 4/j.1600-0587.2003.03554.x

Kinlock NL, Prowant L, Herstoff EM et al (2018) Explaining global variation in the latitudinal diversity gradient: meta-analysis confirms known patterns and uncovers new ones. Glob Ecol Biogeogr 27:125-141. https://doi.org/10.1111/geb.12665
Kosten S, Kamarainen A, Jeppesen E et al (2009a) Climate-related differences in the dominance of submerged macrophytes in shallow lakes. Glob Chang Biol 15:2503-2517. https://doi.org/10.11 11/j.1365-2486.2009.01969.x

Kosten S, Lacerot G, Jeppesen E et al (2009b) Effects of submerged vegetation on water clarity across climates. Ecosystems 12:11171129. https://doi.org/10.1007/s10021-009-9277-x

Kosten S, Jeppesen E, Huszar VLM et al (2011) Ambiguous climate impacts on competition between submerged macrophytes and phytoplankton in shallow lakes. Freshw Biol 56:1540-1553. https:// doi.org/10.1111/j.1365-2427.2011.02593.x

Kraft NJB, Comita LS, Chase JM et al (2011) Disentangling the drivers of $\beta$ diversity along latitudinal and elevational gradients. Science 80(333):1755-1758. https://doi.org/10.1126/science.1208584

Lacoul P, Freedman B (2006) Environmental influences on aquatic plants in freshwater ecosystems. Environ Rev 14:89-136. https:// doi.org/10.1139/a06-001

Legendre P, Gallagher ED (2001) Ecologically meaningful transformations for ordination of species data. Oecologia 129:271-280. https ://doi.org/10.1007/s004420100716

Leibold MA, Chase J (2018) Metacommunity ecology, vol 59. Princeton University Press, Princeton

Leibold MA, Holyoak M, Mouquet N et al (2004) The metacommunity concept: a framework for multi-scale community ecology. Ecol Lett 7:601-613. https://doi.org/10.1111/j.1461-0248.2004.00608 . $\mathrm{x}$

Lewin WC, Mehner T, Ritterbusch D, Brämick U (2014) The influence of anthropogenic shoreline changes on the littoral abundance of fish species in German lowland lakes varying in depth as determined by boosted regression trees. Hydrobiologia 724:293-306. https://doi.org/10.1007/s10750-013-1746-8

Meyerson LA, Mooney HA (2007) Invasive alien species in an era of globalization. Front Ecol Environ 5:199-208. https://doi. org/10.1890/1540-9295(2007)5\%5b199:IASIAE\%5d2.0.CO;2

Mikulyuk A, Sharma S, Van Egeren S et al (2011) The relative role of environmental, spatial, and land-use patterns in explaining aquatic macrophyte community composition. Can J Fish Aquat Sci 68:1778-1789. https://doi.org/10.1139/f2011-095

Nathans LL, Oswald FL, Nimon K (2012) Interpreting Multiple Linear Regression: a Guidebook of variable importance. Pract Assess, Res Eval 17:1-19. https://doi.org/10.3102/00346543074004525

Netten JJC, van Zuidam J, Kosten S, Peeters ETHM (2011) Differential response to climatic variation of free-floating and submerged macrophytes in ditches. Freshw Biol 56:1761-1768. https://doi. org/10.1111/j.1365-2427.2011.02611.x

Nimon K, Oswald FL, Roberts JK (2013) Interpreting regression effects. R package version 2.0-0.http://cran.r-project.org/web/ packages/yhat/index.html

O'Hare MT, Gunn IDM, Chapman DS et al (2012) Impacts of space, local environment and habitat connectivity on macrophyte communities in conservation lakes. Divers Distrib 18:603-614. https ://doi.org/10.1111/j.1472-4642.2011.00860.x

O'Reilly CM, Rowley RJ, Schneider P et al (2015) Rapid and highly variable warming of lake surface waters around the globe. Geophys Res Lett 42:10773-10781. https://doi.org/10.1002/2015G L066235

Oksanen J, Blanchet FG, Kindt R, Legendre P, Minchin PR, O'Hara RB, Simpson GL, Solymos P, Stevens MHH, Wagner H (2013) Vegan: community ecology package. https://cran.r-project.org/ web/packages/vegan/index.html

Ordonez A, Svenning JC (2016) Strong paleoclimatic legacies in current plant functional diversity patterns across Europe. Ecol Evol 6:3405-3416. https://doi.org/10.1002/ece3.2131

Padial AA, Ceschin F, Declerck SAJ et al (2014) Dispersal ability determines the role of environmental, spatial and temporal 
drivers of metacommunity structure. PLoS ONE 9:1-8. https:// doi.org/10.1371/journal.pone.0111227

Peres-Neto PR, Legendre P, Dray S, Borcard D (2006) Variation partitioning of species data matrices: estimation and comparison of fractions. Ecology 87:2614-2625. https://doi.org/10.1890/00129658(2006)87\%5b2614:VPOSDM\%5d2.0.CO;2

Petrocelli JV, Cohen BH, Wampold A (2003) Problems and possible remedies. Meas Eval Couns Dev 36:9-22

Ray-Mukherjee J, Nimon K, Mukherjee S et al (2014) Using commonality analysis in multiple regressions: a tool to decompose regression effects in the face of multicollinearity. Methods Ecol Evol 5:320-328. https://doi.org/10.1111/2041-210X.12166

Ricklefs RE, He F (2016) Region effects influence local tree species diversity. Proc Natl Acad Sci 113:674-679. https://doi. org/10.1073/pnas. 1523683113

Rocha MP, Heino J, Machado-Velho LF et al (2017) Fine spatial grain, large spatial extent and biogeography of macrophyte-associated cladoceran communities across Neotropical floodplains. Freshw Biol 62:559-569. https://doi.org/10.1111/fwb.12885

Rooney N, Kalff J (2000) Inter-annual variation in submerged macrophyte community biomass and distribution: the influence of temperature and lake morphometry. Aquat Bot 68:321-335. https:// doi.org/10.1016/S0304-3770(00)00126-1

Santamaría L (2002) Why are most aquatic plants widely distributed? Dispersal, clonal growth and small-scale heterogeneity in a stressful environment. Acta Oecologica 23:137-154. https://doi. org/10.1016/S1146-609X(02)01146-3

Sass LL, Bozek MA, Hauxwell JA et al (2010) Response of aquatic macrophytes to human land use perturbations in the watersheds of Wisconsin lakes, U.S.A. Aquat Bot 93:1-8. https://doi. org/10.1016/j.aquabot.2010.02.001

Smith TW, Lundholm JT (2010) Variation partitioning as a tool to distinguish between niche and neutral processes. Ecography (Cop) 33:648-655. https://doi.org/10.1111/j.1600-0587.2009.06105.x

Soininen J (2014) A quantitative analysis of species sorting across organisms and ecosystems. Ecology 95:3284-3292. https://doi. org/10.1890/13-2228.1.sm

Søndergaard M, Jeppesen Erik J, Jens P (2005) Pond or lake: does it make any difference? Arch für Hydrobiol 162:143-165. https:// doi.org/10.1127/0003-9136/2005/0162-0143

Søndergaard M, Phillips G, Hellsten S et al (2013) Maximum growing depth of submerged macrophytes in European lakes. Hydrobiologia 704:165-177. https://doi.org/10.1007/s10750-012-1389-1

Soons MB, Van Der Vlugt C, Van Lith B et al (2008) Small seed size increases the potential for dispersal of wetland plants by ducks. J Ecol 96:619-627. https://doi.org/10.111 1/j.1365-2745.2008.01372.x

Souffreau C, Van der Gucht K, van Gremberghe I et al (2015) Environmental rather than spatial factors structure bacterioplankton communities in shallow lakes along a $>6000 \mathrm{~km}$ latitudinal gradient in South America. Environ Microbiol 17:2336-2351. https:// doi.org/10.1111/1462-2920.12692

Svenning JC, Normand S, Kageyama M (2008) Glacial refugia of temperate trees in Europe: insights from species distribution modelling. J Ecol 96:1117-1127. https://doi.org/10.111 1/j.1365-2745.2008.01422.x

Tanner CC, Clayton JS, Harper LM (1986) Observations on aquatic macrophytes in 26 northern New Zealand lakes. New Zeal J Bot 24:539-551. https://doi.org/10.1080/0028825X.1986.10409941

Thomaz SM, Souza DC, Bini LM (2003) Species richness and beta diversity of aquatic macrophytes in a large subtropical reservoir (Itaipu Reservoir, Brazil): the influence of limnology and morphometry. Hydrobiologia 505:119-128. https://doi.org/10.1023/ B:HYDR.0000007300.78143.e1

Tonkin JD, Heino J, Sundermann A et al (2016) Context dependency in biodiversity patterns of central German stream metacommunities. Freshw Biol 61:607-620. https://doi.org/10.1111/fwb.12728

Van Kleunen M, Dawson W, Essl F et al (2015) Global exchange and accumulation of non-native plants. Nature 525:100-103. https:// doi.org/10.1038/nature14910

Viana DS, Santamaría L, Schwenk K et al (2014) Environment and biogeography drive aquatic plant and cladoceran species richness across Europe. Freshw Biol 59:2096-2106. https://doi. org/10.1111/fwb. 12410

Vilmi A, Alahuhta J, Hjort J et al (2017) Geography of global change and species richness in the North. Environ Rev 25:184-192. https ://doi.org/10.1139/er-2016-0085

Wagner T, Soranno PA, Webster KE, Cheruvelil KS (2011) Landscape drivers of regional variation in the relationship between total phosphorus and chlorophyll in lakes. Freshw Biol 56:1811-1824. https://doi.org/10.1111/j.1365-2427.2011.02621.x

Wang J, Soininen J, Zhang Y et al (2011) Contrasting patterns in elevational diversity between microorganisms and macroorganisms. J Biogeogr 38:595-603. https://doi.org/10.111 $1 / j .1365-2699.2010 .02423 . x$

Willby NJ, Abernethy VJ, Demars BOL (2000) Attribute-based classification of European hydrophytes and its relationship to habitat utilization. Freshw Biol 43:43-74. https://doi.org/10.104 6/j.1365-2427.2000.00523.x

Willis KJ, Whittaker RJ (2002) Species diversity—scale matters. Science 80(295):1245-1247. https://doi.org/10.1126/science.10673 35

Winegardner AK, Jones BK, Ng ISY et al (2012) The terminology of metacommunity ecology. Trends Ecol Evol 27:253-254. https:// doi.org/10.1016/j.tree.2012.01.007

\section{Affiliations}

\section{Janne Alahuhta ${ }^{1,2}$ (1) Marja Lindholm ${ }^{1}$. Claudia P. Bove ${ }^{3} \cdot$ Eglantine Chappuis $^{4} \cdot$ John Clayton $^{5} \cdot$ Mary de Winton $^{5}$. Tõnu Feldmann ${ }^{6}$. Frauke Ecke $^{7,8}$ • Esperança Gacia ${ }^{4} \cdot$ Patrick Grillas $^{9} \cdot$ Mark V. Hoyer $^{10}$ • Lucinda B. Johnson ${ }^{11}$. Agnieszka Kolada ${ }^{12} \cdot$ Sarian Kosten ${ }^{13} \cdot$ Torben Lauridsen $^{14} \cdot$ Balázs A. Lukács $^{15} \cdot$ Marit Mjelde $^{16} \cdot$ Roger P. Mormul $^{17}$. Laila Rhazi $^{18}$ • Mouhssine Rhazi ${ }^{19}$. Laura Sass ${ }^{20}$. Martin Søndergaard ${ }^{14}$. Jun Xu ${ }^{21}$. Jani Heino ${ }^{22}$}

1 Geography Research Unit, University of Oulu, P.O. Box 3000, 90014 Oulu, Finland

2 Finnish Environment Institute, Freshwater Centre, P.O. Box 413, 90014 Oulu, Finland
3 Departamento de Botânica, Museu Nacional, Universidade Federal do Rio de Janeiro, Quinta da Boa Vista, Rio De Janeiro, RJ 20940-040, Brazil

4 Centre d'Estudis Avançats de Blanes (CEAB), Consejo Superior de Investigaciones Científicas (CSIC), C/accés a la Cala St. Francesc 14, 17300 Blanes, Spain 
5 National Institute of Water and Atmospheric Research Limited, P.O. Box 11115, Hamilton, New Zealand

6 Centre for Limnology, Institute of Agricultural and Environmental Sciences, Estonian University of Life Sciences, 61117 Rannu, Tartumaa, Estonia

7 Department of Aquatic Sciences and Assessment, Swedish University of Agricultural Sciences (SLU), P.O. Box 7050, 75007 Uppsala, Sweden

8 Department of Wildlife, Fish and Environmental Studies, Swedish University of Agricultural Sciences (SLU), 90183 Umeå, Sweden

9 Tour du Valat, Research Institute for the conservation of Mediterranean wetlands, Le Sambuc, 13200 Arles, France

10 Fisheries and Aquatic Sciences, School of Forest Resources and Conservation, Institute of Food and Agricultural Services, University of Florida, 7922 NW 71st Street, Gainesville, FL 32609, USA

11 Natural Resources Research Institute, University of Minnesota Duluth, 5013 Miller Trunk Highway, Duluth, MN 55811, USA

12 Department of Freshwater Protection, Institute of Environmental Protection-National Research Institute, Krucza 5/11D, 00-548 Warsaw, Poland

Department of Aquatic Ecology and Environmental Biology, Institute for Water and Wetland Research, Radboud University, Heyendaalseweg 135, 6525AJ Nijmegen, The Netherlands
14 Department of Bioscience, Aarhus University, Vejsøvej 25, 8600 Silkeborg, Denmark

15 Department of Tisza River Research, MTA Centre for Ecological Research, Bem tér 18/C, Debrecen 4026, Hungary

16 Norwegian Institute for Water Research (NIVA), Gaustadalléen 21, 0349 Oslo, Norway

17 Department of Biology, Research Group in Limnology, Ichthyology and Aquaculture-Nupélia, State University of Maringá, Av. Colombo 5790, Bloco H90, CEP-87020-900 Mringá, PR, Brazil

18 Laboratory of Botany, Mycology and Environment, Faculty of Sciences, Mohammed V University in Rabat, 4 avenue Ibn Battouta, B.P. 1014 RP, Rabat, Morocco

19 Faculty of Science and Technology, Department of Biology, Moulay Ismail University, PB 509, Boutalamine, Errachidia, Morocco

20 Illinois Natural History Survey, Prairie Research Institute, University of Illinois, 1816 South Oak Street, Champaign, IL 61820, USA

21 Institute of Hydrobiology, Chinese Academy of Sciences, Wuhan 430070, China

22 Finnish Environment Institute, Biodiversity Centre, P.O. Box 413, 90014 Oulu, Finland 